\title{
Online Self-regulated Learning Strategies for College English Learners
}

\author{
Qu Hui \\ Fundamental Department, Engineering University of PAP, Xi'an 710086, China \\ qh3798150@sina.com
}

Keywords: online learning environments, self-regulated English learning, learning strategies

Abstract: With the development of educational informatization, a brand-new online learning platform has been provided for college English learning. It is very important to cultivate learners' self-regulated learning in online learning environments, and learners' self-regulated learning strategy is the key to the success of online college English learning. This paper presents the self-regulated learning strategies, not only to promote the effects and strategies of English learning, but also to enable English learners to explore and innovate through the use of learning strategies, thus benefiting from life-long learning.

\section{Introduction}

In the 21st century, it becomes a new trend for people to use online learning to acquire knowledge and cultivate their ability. Compared with the traditional learning environment, the online learning environment has the advantages of sharing, interaction, autonomy, advancement, renewability. Although the infrastructure of information technology has undergone tremendous changes, and the information technology so far has played a positive role in English learning, it has not promoted English learners' self-regulated learning effectively yet. The rapid development of information technology has provided an unprecedented possibility for the reform of college English learning strategies. However, teachers' understanding of English learning strategies in the online environment only remains at the level of concrete operation and simple imitation, thus failing to realize the true connotation of self-regulated English learning strategies in the online environment. Therefore, the study of self-regulated learning strategies for learners in the online environment is of great guiding and practical significance to college English course.

\section{Self-regulated English learning in the online environment}

Self-regulated English learning in the online environment is different from the self-regulated learning both in a narrow sense and in the generalized sense. Namely, it is a learning activity to acquire language knowledge and skills consciously, actively and subjectively, to develop intelligence and cultivate ability, in which individual learning is the main form, with centralized face-to-face 
instruction as the guide, multiple-media learning as the auxiliary, and interactive and group cooperative learning as a supplement, and with the help of learning support system and advanced teaching facilities. This self-regulated learning fully embodies that learners and learning are the center of education, and also has the distinct characteristics of language learning. Learners use a variety of multi-media materials to help their individualized and active learning. Generally speaking, they have English language as the main teaching materials, with video, audio, multimedia courseware and network courses supplemented, and they arrange English learning autonomously. Learners should receive the necessary face-to-face tutoring from teachers and the complete learning support services provided by schools, make full use of multimedia resources, adopt various learning methods, and actively acquire English knowledge and skills.

Besides, learners can form a study group for cooperative learning online or use computer network for interactive learning. Learners can independently determine the learning content, make free choice of learning time and methods, but should complete the required course assignments online, and get corrections and feedback timely. Whenever learners have any questions or requests, they can put forward them online and get feedbacks from teachers. It can be seen that self-regulated learning in the network environment is based on the principle of decentralized and individual learning. It combines the guidance with assistance and collective learning, and implements the comprehensive utilization of various learning media. It also closely combines the language knowledge learning with skill practice.

\section{Self-regulated learning strategies in college English in the online environment}

Online learning environment not only emphasizes the technical support for learning, but also emphasizes the deepest influence on the students on the Internet. Self-regulated learning strategies in the online environment do not mean only the learning through the internet which is different from the traditional classroom. It is a general term for learners' learning activities and psychological tendencies in the online environment.

In the online environment, self-regulated learning strategies for college English should be emphasized. Self-regulated learning strategies in college English in the online environment refer to the procedures, rules, methods, techniques and control modes of learners' effective learning in language learning activities. It is not only implicit rules but also explicit procedures. Its core components are cognitive strategies and reflective cognition.

Self-regulated learning strategy is an important measure of individual learning ability and one of the important factors that attribute to the effect of online English learning. It is obvious that controllability and methodology are the essential attributes of self-regulated learning strategies. Its basic characteristics are as follows: first, self-regulated learning strategies are formed with the development of English learning activities; secondly, self-regulated learning strategies are an operating system to help English learners integrate learning methods and learning content; thirdly, self-regulated learning strategies will change with learners' expectations of English learning goals and content. As to the teaching in the educational informationization environment, self-regulated learning strategy is the most core link, and it is the key link to promote learners to complete the meaningful construction of their English language knowlege and skills.

\subsection{Interactive learning strategies in the online environment}

In the online environment, college English learners can independently make use of online resources such as databases, electronic publications and downloadable application programs for personal communication. They can also use publishing technologies such as E-mail, BBS, FTP, etc., 
to present their opinions on the Internet, and to answer questions raised by teachers.It is easier for English learners to get access to asynchronous communication on the network and to control their language learning process.

The most important feature of online English learning lies in its instant two-way communication. The network can link teachers and learners, even more other learners together timely by the use of information technology, so that the two-dimensional or multi-dimensional participation can be carried out simultaneously by the interactors. The interaction in online English learning is a two-way communication among two or more learners in the learning process, in order to improve learning tasks and teaching and establish social relations. Although this interaction doesn't occur in the same physical location, the synchronous information dissemination and the same task can provide the common virtual activity background for the interactors. Therefore, the interaction among English learners can not only promote their acquirement of language knowledge and skills, but also enable English learners to pay more attention to the important role of interaction in the social environment.

In online English learning, learners' interaction involves using various information technologies, getting access to learning materials, and communication with teachers and other learners. This is called the interaction between human and learning system. The Internet provides learners with vivid English learning environment. This environment helps to maintain learners' interest and provides a more natural language learning atmosphere. In this online English learning environment, the system interacts with individual learners and tries to personalize the learning according to learners' needs. In addition, new language knowledge and skills acquired through online learning are associated with learners' inner reactions and their prior language knowledge and skills, which is called self-interaction.

\subsection{Cooperative learning strategie in the online environment}

Online cooperative English learning refers to the language learning process in which learners interact and cooperate each other to achieve a deeper understanding of the same learning content and learning task by the use of networks and multimedia technologies. Constructivism is the theoretical basis of cooperative learning in the online environment. In online cooperative English learning, with the help of Internet, and Intranet, learners under the guidance of teachers, jointly complete a certain language learning task. In this process, with a certain network interactive platform, learners give full play to their collective synergy effort with division of labor, cooperation, and mutual assistance.

Online cooperative English learning is a learner-centered and self-regulated learning model, but this does not mean that teachers no longer control learners. On the contrary, teachers play the role of organizers, instructors and promoters of cooperative learning, who should not only make learners develop their habit of self-conscious learning and self-regulated cooperation on the network, but also actively help learners form a set of effective online English learning methods suitable for their own, and thus improving learners' self-regulated English learning and problem-solving ability.

In the online environment, English learners are no longer an isolated learning individual, but rather a group member who participates in a wider range of consultative learning activities. The cooperative learning group is under the guidance and support of teachers, and its main learning task is to accomplish a certain research by using interactive and multimodal ways to construct learners' language knowledge and skills. That cooperative group is essentially a complete cognitive system, and each learner with cooperative learning strategies is involved to achieve the common goal and build the learning community which will be a more effective organization of English learning.

In the online English learning, the multilateral communication among learners can be realized by network discussion. Learners can participate in discussions and exchanges, then post in their ideas under the organization and guidance of teachers. One's speech can be browsed by the others who 
participate in the discussion at any time. Everyone can browse the web page to participate in discussions and speeches. Moreover, learners can also discuss and communicate in the chat rooms in a harmonious environment. In this relaxed and free environment, English learners can choose the topic they are interested in to fully express themselves, so that they can improve their reading, listening, speaking, and writing skills. With the development of information technology, individual learning, online counseling and other English learning activities, will be more personalized, more accessable.

\subsection{Learning motivation supportive strategies in the online environment}

Online English learning is different from traditional classroom English learning, and it is an independent learner-centered learning. The learning motivation supportive strategies have an impact on online English learning in various aspects. They can not only guide learners' interest, enthusiasm, time, and energy invested in English learning, but also maintain learners' initial positive motivation and keep learners' initiative learning in the process of online self-regulated English learning.

With the virtuality, openness and autonomy of online English learning, learners' learning motivation is different from that measured in traditional classroom learning. First of all, in the online environment, learners' learning motivation is uncertain. In the traditional classroom learning with the fixed learning schedule and interpersonal environment, even if the learners lack the necessary internal incentives, they can obtain relatively stable learning motivation from the outside. However, the online self-regulated English learning lacks those fixed factors in the classroom. Learners' motivation mainly depends on the individual characteristics of learners. In fact, different learners have different personalities, hence there is a strong uncertainty. Secondly, there are individual differences in learners' learning motivation in the online environment. In online self-regulated English learning, motivation stimulation should be based on learners' personal characteristics, and different motivation stimulation strategies should be selected for different learners. Thirdly, English learners' learning motivation in the online environment is dynamic. Learners' learning motivation varies with their learning process. With the true and accurate records of dynamic information and relevant factors of learning motivation, it is convenient for English teachers and learners to observe the learning motivation according to different stages of the learning process, so as to further reflect on and interfere with learning motivation and make it better. Finally, English learners' learning motivation is autonomous in the online environment. The ultimate goal of online self-regulated English learning is to cultivate students into successful strategic learners. Successful Strategic learners can recognize the influence of motivation on themselves and become the main motivators instead of putting their learning responsibility on teachers or others.

\section{Conclusions}

With the advance of information technology, learning strategies are one of the most important factors that directly affect self-regulated learning of English learners. At present, teachers pay more attention to teaching strategies, but put less emphasis on learning strategies in research and teaching practice. Therefore, it is particularly important and necessary to do the research and exploration of online self-regulated learning strategies for college English learners. In the study of online self-regulated learning strategies, English learners should be encouraged to consciously adopt a certain learning strategy or several learning strategies to catch up with the language learning tasks. Moreover, the effective use of learning strategies and timely adjustment, should be considered by teachers from learners' point of view, in order to cultivate learners' self-regulated learning ability and improve their interest and performance in college English learning. 


\section{References}

[1] Salaberry, M. R., The use of technology for second language learning and teaching: A retrospective. Modern Language, Vol. 85(1), (2001)

[2] Oxford, R. L., Teaching and researching language learning strategies (1sted). Harlow, Essex, UK: Pearson Longman, 2011, pp.183-187.

[3] Saks, K., \& Leijen, A., Supporting contrive and metacognitive learningstrategies in technologically enhanced language learning. Estonia Educational Sciences, Vol. 3(2), (2015)

[4] Ou Yang, F., \& Wu, W., Using mixed-modality learning strategies via elearning for second language vocabulary acquisition. Educational Technology \& Society, Vol. 18(3), (2015)

[5] Zhou, Y., Digital vocabulary competition as motivator for learning in CFL classrooms. Technology and Chinese Language Teaching, Vol.7(2), (2016) 